\title{
Stage I Adult Liver Cancer AJCC v7
}

National Cancer Institute

\section{Source}

National Cancer Institute. Stage I Adult Liver Cancer A/CC v7. NCI Thesaurus. Code C94775.

For hepatocellular carcinoma: Stage I includes: T1, N0, M0. T1: Solitary tumor without vascular invasion. N0: No regional lymph node metastasis. M0: No distant metastasis. For intrahepatic cholang iocarcinoma: Stage I includes: T1, N0, M0. T1: Solitary tumor without vascular invasion. N0: No regional lymph node metastasis. M0: No distant metastasis. (from AJCC 7th Ed.) 